\title{
BMI Changes in Russian Adults: The Role of Health Related Behaviors and Spousal Relationships
}

\author{
Sonya Kostova Huffman ${ }^{1, *}$ \\ ${ }^{1}$ Dept. of Economics, Iowa State University, Ames, Iowa, USA \\ *Correspondence: 260 Heady Hall, Dept. of Economics, Iowa State University, Ames, Iowa, \\ 50010, USA. E-mail: skostova@iastate.edu
}

Received: January 22, 2014 Accepted: August 19, 2014 Published: August 28, 2014

doi:10.5296/rae.v6i3.4968 URL: http://dx.doi.org/10.5296/rae.v6i3.4968

\begin{abstract}
The paper investigates the effects of changes in marital status and health related behaviors (smoking and drinking) on the body mass index (BMI) in Russian adults over a ten-year period. Smoking and drinking behavior changes have played an important part in health status changes over 1994 to 2004 . The results indicate that the individual weight/BMI changes asymmetrically in health determinants; the sign and the magnitude of the response are different depending on the starting point and whether there is an increase or a decrease in the explanatory variable. Males' BMI decreases with smoking and increases with quitting smoking, but females' BMI increases with drinking alcohol and decreases with stopping drinking. Losing a partner decreases only the females' BMI, but gaining a spouse/partner is associated with increases in BMI for both genders. For married females and males, the change in spousal BMI is significantly positively related. Understanding interactions between individual health-related behaviors and the set of determinants that contribute to such behaviors is a fundamental step in the design of effective interventions.
\end{abstract}

Keywords: Health related behaviors, BMI, Asymmetric response, Russia 


\section{Introduction}

Over the past century major improvements in population health of developed countries have been recorded, including increased life expectancy by as much as 25-30 years. People have gained in height and weight over time also. However, industrialization and progress are accompanied by an increase in chronic diseases, especially those age-related. At the same time, changes in life and work patterns have resulted in less physical activity and physical labor. The computer and the TV are two obvious reasons why people spend many more hours of the day seated and relatively inactive more so than generations ago.

Now, there are more than 1 billion overweight adults, with at least 300 million of them being obese. Increased consumption of more energy-dense foods with high levels of sugar and saturated fats, combined with reduced physical activity, have caused obesity rates to rise significantly since 1980, not only in North America and the United Kingdom, but also in Eastern Europe, the Middle East, China and Australia (WHO, 2010). Therefore, the prevalence of obesity has risen dramatically not only in high income countries but in middle and low-income countries. A number of research papers have discussed the determinants and consequences of obesity in developed countries (Chou et al., 2004; Lakdawalla et al., 2005; Rashad et al., 2006, Huffman et al. 2010). The trend of increasing obesity in transition countries has been analyzed for Russia (Zohoori et al. 1998, Jahns et al. 2003, Huffman and Rizov 2007, Huffman and Rizov 2010, Staudigel 2010) and other transition economies (Kalediene and Petrauskiene 2004, Koziel et al. 2004).

Studies by Sobal et al. (2003) and Averett et al. (2008) have examined the relationship between marital status changes and body weight changes among US adults. They find that unmarried women at the baseline who married at follow-up gained more weight than women married at both times. Men who remained divorced and men who became widowed lost more weight than men married at both times. BMI increases for both women and men during marriage and in the course of a cohabitating relationship.

Another body of recent research focuses on the role of social interactions in the spread of obesity (e.g. Christakis and Fowler, 2007; Trogdon et al. 2008). The existing literature on peer effects suggests that peers influence health behaviors (smoking, alcohol and drug use) among young people (Evans et al. 1992; Norton et al. 1998, Powel et al. 2005; Lundborg 2006). Christakis and Fowler (2007) and Trogdon et al. (2008) find that social networks significantly impact the likelihood of becoming obese, while Cohen-Cole and Fletcher (2008) reject the hypothesis that weight status can spread from person to person. It is possible that age may impact on the importance of social networks. The influence of social networks may also differ by country. Therefore, the goal of this paper is to investigate the effects of changes in marital status and health related behaviors (smoking and drinking) on the body mass index (BMI) in Russian adults over a ten-year period. The main contribution of the study is extending the literature on the relationship between health (obesity) and changes in behaviors and spousal relationships in transition economies by using data from the Russian Longitudinal Monitoring Survey (RLMS).

The paper is organized as follows. Section 2 discusses the relationships between lifestyles 
and obesity. Section 3 presents the conceptual framework. Section 4 describes the data and the empirical model. Section 5 presents the main results and Section 6 concludes.

\section{Health Related Behaviors and Obesity}

Health related behaviors, such as poor diets, sedentary life, and resulting obesity are adversely affecting population healths in the world. Obesity and the prevalence of chronic disease linked to obesity, such as diabetes and cardio-vascular disease have increased in the last decades (Sassi and Hurst, 2008). Changes in food processing and production and in agricultural and trade policies have affected the daily diet of hundreds of millions of people. The consumption of tobacco, alcohol, and processed or "fast" foods fits easily into the lifestyle patterns. At the same time in the most industrialized countries of North America, Europe, and the Asian Pacific, at least one-third of all disease burdens are caused by tobacco, alcohol, blood pressure, cholesterol, and obesity.

Global alcohol consumption has increased in recent decades, with most or all of this increase occurring in developing countries (WHO, 2002). Worldwide, alcohol caused 1.8 million deaths, equal to $4 \%$ of the global disease burden; the proportion was greatest in North and South America, and Europe. Alcohol was estimated to cause, worldwide, $20-30 \%$ of esophageal cancer, liver disease, epilepsy, motor vehicle accidents, and homicide and other intentional injuries. The WHO 2002 report finds that physical inactivity causes about $15 \%$ of some cancers, diabetes, and heart disease. Lifestyles play an important role in determining chronic diseases and lifestyle changes are likely to be responsible for a significant proportion of their increase over time. Smoking is estimated to be responsible for $22 \%$ of cardiovascular diseases in industrialized countries, as well as for the majority of cancers; high cholesterol accounts for $5-12 \%$, while overweight and obesity account for $8-15 \%$ of the burden of disease (WHO, 2002). People who eat plenty of fruits and vegetables, drink alcohol in small quantities, do not smoke, and are physically active, have a risk of death that is less than one fourth of the risk of those who have invariably unhealthy habits (Khaw et al., 2007).

Therefore, lifestyle choices have played an important part in health status and it is important to identify opportunities for intervening on these choices in order to improve individual and social welfare. To understand the channels through which chronic diseases are generated, an assessment of individual determinants, interactions between structural determinants (social norms and socioeconomic conditions) and behavioral determinants (lifestyle choices) is required. Lifestyle choices are shown to be closely linked with a significant portion of the morbidity and mortality generated by chronic diseases (WHO, 2002).

Democratic reforms since 1991 brought many changes and challenges to the everyday life of the average Russian. The country opened to the world and many new food products began to flood into the Russian market, including "fast food" or "junk foods" rich in fats and sugar, Big-Macs, chips, snacks, etc. That led to increased consumption of more bread, flour, and other foods of poor quality. Increased advertising of imported foods, cigarettes, and alcohol have contributed to a growth in consumption of Western style goods. The lifestyles literature on Russia discusses the pattern of excessive alcohol consumption, heavy smoking, high fat 
diet and lack of physical exercise - characteristics of middle-age working males (Cockerham, 2000, 2002; Palosuo, 2000). In 1994, Russia had the highest per capita pure alcohol consumption in the world, 14.5 liters per year, and the adult males that comprised $25 \%$ of the population consumed 90\% of the alcohol (Cockerham, 2002). Bobrova et al. (2010) investigate the gender differences in drinking patterns in Russia and conclude that women drink less often and much smaller quantities than of men. These differences were largely explained by gender roles in the society. The study by Palosuo (2000) also confirms the existence of sex differences in health related lifestyles in Russia. Cigarette consumption is also higher in Russia than in the Western countries and as consequence the males deaths from lung cancer are extremely high (Cockerham, 2000).

Dietary choices also affect health. Obesity is a result of imbalance between energy expenditure and energy intake. During the transition, the diet and lifestyles of Russians changed. Russian households responded to the income and price changes as a result of the transition to a market economy (Huffman and Rizov, 2007). The energy intake has increased while the energy expenditure has decreased, a trend developed in other industrialized countries. Voronina (2009) points out that "in Russia, the problem of obesity is now nearly as serious as the problem of alcoholism." Stillman (2006) reviews the literature on health and nutrition in countries transitioning to a market economy, which suggest that the early years of transition associated with stress, smoking, and increased alcohol consumption (in the presence of low real alcohol prices following the hyperinflation of the 1990's) are the likely causes for increased mortality in Russia. Therefore, the individual, demographic, and cultural determinants of optimal nutrition can help develop health policies and public health programs to improve people's health and well being in Russia, and to promote healthier lifestyles. This should include the reduction of smoking, poor nutrition, alcohol abuse, and physical inactivity.

\section{Conceptual Framework}

The conceptual framework is based on an economic approach of individual health related behaviors as a result of choices on food, tobacco, alcohol, and physical activity or leisure time, in the light of opportunity costs and other incentives. Individuals derive utility from many forms of consumption. Health related behaviors and other consumer choices are based on preferences that are subject to many influences including the family environment, education, peer groups, social networks, work environment, and the physical environment. The individuals are affected by the determinants of health and the way these determinants change over time. The biological characteristics and genetic makeup of individuals play an important role in determining their health status, but the effects of those characteristics are often changed by socioeconomic and physical environmental factors, and by the individual's interactions with these environments.

This paper is focused on the social determinants of health in Russian adults. The social health determinants include individual choice and behavior; education, culture, labor markets, unemployment, the characteristics of social and economic context in which people live and 
work. Education is a powerful determinant of health. Parental education as well as an individual's own education is strongly associated with lifestyle choices, health status, and longetivity. Education has also had a strong effect on wages, which itself influences health. Therefore, understanding the relation among these determinants is also important.

Following the productive household models of health developed by Rosenzweig and Schultz (1982), Grossman (2000), Huffman and Rizov (2010) and the agricultural household model developed by Huffman (1991), the individual obtains utility:

$$
\mathrm{U}=\mathrm{U}(\mathrm{G}, \mathrm{BMI}, \mathrm{L} ; \mathrm{Z}, \mu)
$$

which depends on the consumption of goods (G) including food, alcohol, cigarettes, etc., BMI, leisure (L), physical wellbeing, affective attributes (love and family situations such as loss of a partner or children leaving home) and other socioeconomic variables ( $Z$ ), and unobservable individual characteristics such as genetic factors $(\mu)$. The individual's BMI production function is:

$$
\mathrm{BMI}=\mathrm{f}(\mathrm{G}, \mathrm{L}, \mathrm{Z}, \mu) \text {. }
$$

The individual maximizes utility subject to the technology of health production, prices, cash income and human time constraint. After substituting the optimal demand functions $G^{*}$ and $\mathrm{L}^{*}$ into the BMI production function we obtain the individual's BMI supply function:

$$
\mathrm{BMI}^{*}=\mathrm{f}_{\mathrm{S}}\left(\mathrm{G}^{*}, \mathrm{~L}^{*}, \mathrm{Z}, \mu^{\prime}\right) \text {. }
$$

Based on the theoretical model next we will test the following hypothesis: the relationship between BMI and various determinants is not symmetric. It depends on the starting point, e.g. is the starting point normal BMI or under/overweight, and second, are the changes in a determinant positive or negative. It is frequently assumed that the response of economic variables to determinants is symmetric. This means that a positive change in an exogenous economic variable has the same effect on an outcome as a decrease. The focus of the paper will be to test the notion of asymmetric responses.

\section{Data and Empirical Model}

Data from the RLMS for 1994 and 2004 are used to investigate how changes in marital status and health related behaviors (smoking and drinking) affect changes in BMI in Russia. Ten year time period allows to analyze long term changes in health related behaviors and BMI. The RLMS is a nationally representative household survey that annually samples the population of dwelling units. The data collected include a wide range of information concerning household characteristics such as demographic composition, income, and expenditures. Data on individuals includes employment, anthropometric measures, health status, nutrition, alcohol consumption, and medical problems.

Following the theoretical model, the technical relationship between the changes in BMI (continuous variable) and a change in marital status, e.g. losing a partner, gaining a partner, and changes in health related behaviors, as reflected in cigarette and alcohol consumption is 
established. The panel fixed effect analysis corrects the bias associated with unobserved characteristics. If an individual's selection into drinking, smoking, and employment is due only to time invariant characteristics of the individual which may be observed or unobserved, then the fixed effect estimator is consistent. Also, a fixed effect panel model controls for sample selection that depends only on time-invariant characteristics (Cameron and Trivedi, 2005).

The individual BMI supply equation is estimated by the following dynamic equation:

$$
\mathrm{BMI}_{\mathrm{i} 2004}-\mathrm{BMI}_{\mathrm{i} 1994}=\alpha \mathrm{BMI}_{i 1994}+\beta \mathbf{X}_{\mathrm{i} 1994}+\delta\left(\mathbf{X}_{\mathrm{i} 2004}-\mathbf{X}_{\mathrm{i} 1994}\right)+\varepsilon
$$

where $\mathbf{X}$ is a vector of determinants of the changes in BMI; $\alpha, \beta$ and $\delta$ s are the coefficients to be estimated and $\varepsilon$ is the error term. The vector $\mathbf{X}$ includes the socio economic determinants of health - age, age squared to allow for nonlinear effect of age, education (approximated by the type of schooling, e.g. high school and university), urban residence, marital status, household size, number of children, medical problems (whether the individual has had a health problem in the last 30 days), employment (participation in the labor force in the last 30 days), income, life satisfaction (from 1 to 5 , with 1 being absolutely satisfied and 5 being absolutely not satisfied). Life satisfaction measures responses to the question "To what extent are you satisfied with your life in general at the present time?" The change of $\mathbf{X}$ includes change in income, number of kids (less or more), smoking (become a smoker, and stopped smoking), drinking (started drinking and stopped consuming alcohol), employment status (gained a job and lost a job), marital status (gained a partner or lost a partner) and spousal BMI (when the spouse is present in both years 1994 and 2004). This study investigates the changes in smoking and drinking as quitting/starting smoking and drinking. We exclude the less significant changes of decrease or increase in the amount of smoking/drinking, which could be researched in the future. Table 1 presents the definitions and the standard deviations of the variables used in the analyses. The model presented in equation (2) is estimated by gender to account for male/ female differences in responses to health determinants. Since only data for 1994 and 2004 years are available for this study, the best econometric model is the first difference estimator. The first difference estimator is obtained by performing an Ordinary Least Squares on first differences of variables with clustered robust standard errors.

The mean BMI at the beginning of the period in 1994 for females is 27.13, and for males is 25.1. According to the WHO, individuals with a BMI over $25 \mathrm{~kg} / \mathrm{m}^{2}$ are defined as overweight, and with a BMI of over $30 \mathrm{~kg} / \mathrm{m}^{2}$ as obese. Therefore in 1994, the average Russian woman and man is classified as overweight. The average change in BMI over the ten-year period is higher for females (1.38) than for a male (0.83). In 1994, sixty percent of men were smokers, while only $6 \%$ of women smoked cigarettes. During the analyzed period from 1994 to 2004, 7.3\% of men quitted smoking and 7.2\% started smoking, while $1.4 \%$ of women quitted smoking and $4.2 \%$ started to smoke. The advertisement of foreign cigarettes and lifestyles, especially in metropolitan areas like Moscow, resulted in more women adopting western lifestyles. A greater number of individuals drink alcohol rather than smoke cigarettes in Russia; 76.6\% of males and 48.3\% females consumed alcohol in 1994. 


\section{MInstitute ${ }^{\text {Macrothink }}$}

Table 1. Variable definitions and summary statistics

\begin{tabular}{|c|c|c|c|c|c|}
\hline Variable & Definition & Mean & Std. Dev. & Mean & Std. Dev. \\
\hline & & \multicolumn{2}{|c|}{ male $=1294$} & \multicolumn{2}{|c|}{ female $=2002$} \\
\hline chabmi & Change in BMI from1994 to 2004 & 0.825 & 2.901 & 1.380 & 3.410 \\
\hline BMI & BMI in 1994 & 25.106 & 3.693 & 27.128 & 5.106 \\
\hline bmisq & BMI in 1994 squared & 643.947 & 195.914 & 761.971 & 291.691 \\
\hline Age & Age in years in 1994 & 41.661 & 13.701 & 45.447 & 15.302 \\
\hline agesq & Age in years in 1994 squared & 1923.232 & 1214.756 & 2299.490 & 1450.806 \\
\hline Nhhm & Number of household members in 1994 & 3.660 & 1.523 & 3.322 & 1.558 \\
\hline Income & Total real income in 1994 & 2603.840 & 2387.443 & 2570.997 & 2299.871 \\
\hline Chainc & Change in real income from 1994 to 2004 & 458.120 & 10274.440 & 80.211 & 10049.190 \\
\hline Smoker & Dummy $=1$ if the individual smokes in 1994 & 0.600 & 0.490 & 0.061 & 0.239 \\
\hline Chasmokeq & Dummy $=1$ if the individual quits smoking 2004 & 0.073 & 0.260 & 0.014 & 0.120 \\
\hline Chasmokes & Dummy $=1$ if the individual starts smoking 2004 & 0.072 & 0.258 & 0.042 & 0.202 \\
\hline Drinker & Dummy $=1$ if the individuals drinks in 1994 & 0.766 & 0.424 & 0.483 & 0.500 \\
\hline Chadrinkq & Dummy $=1$ if the individual quits drinking 2004 & 0.235 & 0.424 & 0.213 & 0.409 \\
\hline Chadrinks & Dummy=1if the individual starts drinking 2004 & 0.116 & 0.320 & 0.132 & 0.339 \\
\hline Work & Dummy=1 if the individual is employed in 1994 & 0.754 & 0.431 & 0.606 & 0.489 \\
\hline Chaworkq & Dummy=1 if the individual stops work 2004 & 0.242 & 0.428 & 0.192 & 0.394 \\
\hline Chaworks & Dummy $=1$ if the individual gets a job in 2004 & 0.067 & 0.251 & 0.063 & 0.243 \\
\hline Nkids & Number of children in the family in 1994 & 0.697 & 0.890 & 0.605 & 0.826 \\
\hline Chakidsm & $\begin{array}{l}\text { Dummy }=1 \text { if the number of children in the family } \\
\text { is higher in } 2004\end{array}$ & 0.242 & 0.428 & 0.177 & 0.382 \\
\hline Chakidsl & $\begin{array}{l}\text { Dummy=1 if the number of children in the family } \\
\text { is lower in } 2004\end{array}$ & 0.257 & 0.437 & 0.250 & 0.433 \\
\hline Married & Dummy $=1$ if the individual is married in 1994 & 0.819 & 0.385 & 0.669 & 0.471 \\
\hline Chamstgainp & Dummy=1 if the individual gains a partner 2004 & 0.092 & 0.289 & 0.064 & 0.246 \\
\hline Chamstlossp & Dummy $=1$ if the individual lost a partner in 2004 & 0.060 & 0.237 & 0.176 & 0.381 \\
\hline Urban & $\begin{array}{l}\text { Dummy }=1 \text { if the individual resides in an urban } \\
\text { area in } 1994\end{array}$ & 0.662 & 0.473 & 0.692 & 0.462 \\
\hline Medical prob & $\begin{array}{l}\text { Dummy }=1 \text { if the individual reports having } \\
\text { medical problems in } 1994\end{array}$ & 0.331 & 0.471 & 0.517 & 0.500 \\
\hline High School & $\begin{array}{l}\text { Dummy=1 if the individual has a high education } \\
\text { (base category is primary education) in } 1994\end{array}$ & 0.356 & 0.479 & 0.318 & 0.466 \\
\hline University & $\begin{array}{l}\text { Dummy }=1 \text { if the individuals has university } \\
\text { education in } 1994\end{array}$ & 0.612 & 0.487 & 0.609 & 0.488 \\
\hline Life_satisfaction & $\begin{array}{l}\text { Dummy variable equal to one if the individual is } \\
\text { satisfied with his/her life in } 1994\end{array}$ & 0.139 & 0.346 & 0.109 & 0.312 \\
\hline Chabmipd & BMI Change from 1994 to 2004 of a partner & 1.246 & 3.135 & 0.375 & 1.985 \\
\hline
\end{tabular}


During the ten year period 1994-2004, 23.5\% of men and $21.3 \%$ of women stopped drinking, while $11.6 \%$ of men and $13.2 \%$ of women started to drink alcohol in Russia. The share of alcohol consumed in the form of vodka is very high in Russia (Treml, 1997). Regarding participation in labor markets, $75.4 \%$ of males and $60.5 \%$ of females were employed in 1994 , while $24.2 \%$ of males and $19.2 \%$ of females did not have a job in 2004 , and an additional $7 \%$ of males and 6\% of females had a job in 2004. The financial crisis of 1998 and the economic contraction led to growing unemployment in Russia. By the end of 1998, Russian unemployment rates had reached close to $12 \%$, having increased from $7.0 \%$ in 1994 . While the 1998 financial crisis cannot be blamed entirely for the unemployment problem, the decline in economic growth set back attempts to reduce it (Cooper, 1999).

Comparing 2004 to $1994,24.2 \%$ of males and $17.7 \%$ of females have more children, and $25.7 \%$ of males and $25 \%$ of females have fewer children. During the same period $9.2 \%$ of men and $6.4 \%$ of women gained a partner, while $6 \%$ of men and $17.6 \%$ of women lost a partner. The emotional stress of losing a loved one, including a partner or a child that has left home to go to college, can impact an individual's weight. About $33 \%$ of males and $51.7 \%$ of females reported having a medical problem in 1994. Only about $14 \%$ of men and $11 \%$ of women reported being satisfied with their life in 1994. Russian people are not satisfied in general with their life-even with the transition changes from centrally planned to market oriented economy, which brought new opportunities and more efficient resource allocation in the economy.

The wife of a male had a larger change in BMI over the ten-year period compared to the husband of a female, 0.375 versus 1.246 which is consistent with the previous observation that females gained more weight over time compared to the males. The correlation coefficient between an individual's change in BMI and his/her spousal's BMI is 0.15 , and the $p$ value for this correlation is 0.0000 , which indicates that the correlation between spousal BMI changes is statistically significantly different from zero. Forty-seven percent of the married couples had an increase in BMI over the decade, and in $13 \%$ of the couples both spouses' BMI decreased. In $25 \%$ of the couples, the female gain weight and the male lost weight, while in $15 \%$ of the couples, the male gained weight and the female lost weight during the ten year period. Therefore, about half of the married couples increased their weight.

\section{Results and Discussion}

Equation (3) is estimated by gender to allow for the differences in response to health determinants, and the results are presented in Table 2.

Age has a significant non linear effect on the decade change in BMI for females. A change in income has significant positive effect on BMI only for the males. Smoking behavior influences significantly only changes in BMI in 2004 for males, while drinking behavior influences significantly changes in BMI for females in 2004. Being a male smoker at the beginning of the period decreases his BMI a decade later by 1.4 percentage points. If a male starts smoking during the decade, his BMI is 1 percentage point lower. 
Table 2. First Difference regression-BMI in Russia

\begin{tabular}{|c|c|c|}
\hline \multicolumn{3}{|c|}{ Dependent variable: change in BMI, 1994 to 2004} \\
\hline Variable & Coefficient (std. error) & Coefficient (std. error) \\
\hline & female & male \\
\hline BMI & $0.1528(0.135)$ & $-0.3900(0.263)$ \\
\hline BMIsq & $-0.0053^{* *}(0.002)$ & $0.0045(0.005)$ \\
\hline Age & $0.1042^{* *}(0.039)$ & $-0.1092^{* *}(0.042)$ \\
\hline Agesq & $-0.0014^{* * *}(0.0004)$ & $0.0009(0.0005)$ \\
\hline Nhhm & $-0.1141^{*}(0.070)$ & $0.0377^{*}(0.068)$ \\
\hline Income & $0.00002(0.0004)$ & $0.0001(0.000)$ \\
\hline Chainc & $0.0000(0.000)$ & $0.00001^{*}(0.000)$ \\
\hline Smoker & $-0.2803(0.394)$ & $-1.3951^{* * *}(0.186)$ \\
\hline Chasmokeq & $0.8137(0.652)$ & $2.0192^{* * *}(0.340)$ \\
\hline Chasmokes & $-0.5965(0.377)$ & $-1.0220^{* * *}(0.327)$ \\
\hline Drinker & $0.4037^{* *}(0.204)$ & $0.0019(0.281)$ \\
\hline Chadrinkq & $-0.4340^{* *}(0.204)$ & $-0.1964(0.189)$ \\
\hline Chadrinks & $-0.0667(0.240)$ & $-0.3317(0.335)$ \\
\hline Work & $0.3868(0.250)$ & $0.5110^{* *}(0.265)$ \\
\hline Chaworkq & $-0.2141(0.213)$ & $0.0539(0.214)$ \\
\hline Chaworks & $0.4896(0.407)$ & $0.7785^{* *}(0.360)$ \\
\hline Nkids & $0.1372(0.147)$ & $-0.1689(0.131)$ \\
\hline Chakidsm & $0.0665(0.223)$ & $-0.0722(0.227)$ \\
\hline Chakidsl & $0.1188(0.223)$ & $0.1249(0.217)$ \\
\hline Married & $0.4310^{* *}(0.194)$ & $0.7049^{* *}(0.300)$ \\
\hline Chamstgainp & $0.6280^{*}(0.333)$ & $0.8005^{* *}(0.363)$ \\
\hline Chamstlossp & $-0.4551^{* *}(0.209)$ & $-0.3518(0.342)$ \\
\hline Urban & $0.2320(0.166)$ & $0.0057(0.165)$ \\
\hline Medical prob & $0.2011(0.150)$ & $0.2080(0.167)$ \\
\hline High school & $-0.0415(0.339)$ & $-0.2360(0.464)$ \\
\hline University & $-0.2823(0.355)$ & $-0.1323(0.471)$ \\
\hline Life_satisfaction & $-0.4350^{*}(0.234)$ & $-0.1306(0.216)$ \\
\hline Chabmipd & $0.1108^{* * *}(0.039)$ & $0.0993^{* * *}(0.027)$ \\
\hline cons & $-0.6745(1.829)$ & $10.1303^{* * *}(3.434)$ \\
\hline R-squared & 0.1271 & 0.1402 \\
\hline
\end{tabular}

Notes: ${ }^{*},{ }^{* *},{ }^{* * *}$ denote statistical significance at the 10,5 and 1 percent level, respectively. Cluster robust standard errors are in parentheses.

If a male quits smoking over the decade, his BMI increases by 2 percentage points. This result is consistent with the previous literature showing that smoking decreases weight. Regarding consumption of alcohol, female drinkers in 1994 saw an increase in BMI by 0.4 
percentage points by 2004. If a female stops consuming alcohol, her BMI decreases by 0.43 percentage points. Drinking alcohol while eating increases the amount of calories consumed which would lead to a gain in weight. Participation in the labor market has only a statistically significant effect on BMI changes for males. Being employed in 1994 increases the BMI a decade later for men by 0.51 percentage points. If the male becomes employed by 2004 , he experiences an increase of 0.78 percentage points.

Being married at the beginning of the period has a positive and statistically significant effect on BMI changes for both genders, but the magnitude is larger for males than females. Male's BMI increases by 0.7 percentage points, but for women the increase is by 0.4 percentage points. A different marital status in 2004 than 1999 where a partner is added increases the male's BMI by 0.8 , and female's BMI by 0.6 percentage points. However, a woman losing a partner or a spouse significantly decreases her BMI by 0.46 percentage points. For a woman, the emotional stress from losing a loved one over the study period reduces her BMI/weight. For married females and males, their changes in BMI are positively related. This evidence supports the previous result by Christakis and Fowler (2007) regarding the spread of obesity with the family. Other studies (Jeffry and Rick, 2002) have also found a positive correlation in weight among spouses.

The results from the estimation of the model as discussed above show that the individual weight/BMI has an asymmetric response to changes in health determinants. Therefore, the sign and the magnitude of the response are different depending on the starting point, and whether there is an increase or a decrease in the explanatory variable.

Surprisingly, we did not find a significant effect of education on the change in BMI for either gender. Being satisfied with life has a statistically negative effect on BMI for females $(0.44$ percentage point). Being unhappy or depressed could increase the consumption of food calories and lead to weight gain.

When people are unhappy, they tend to hide from those problems by eating. Food provides emotional comfort for a lot of people. Food can also be used as a distraction from problems. Depression tends to cause obesity (Cooke and Wardle, 2007). Several studies have shown that stressful environments are associated with poor eating and exercise habits, and poor health outcomes in adults (Greeno and Wing, 1994; Nashitani and Sakakibara, 2006).

\section{Conclusions and Policy Implications}

The goal of this paper is to investigate the effects of changes in marital status and health related behaviors (smoking and drinking) on the body mass index (BMI) in Russian adults over a ten-year period. Changes in health related behavior have played an important part in health status changes over 1994 to 2004. The results indicate that the individual weight/BMI changes asymmetrically in health determinants. Therefore, the sign and the magnitude of the response are different depending on the starting point and whether there is an increase or a decrease in the explanatory variable. Smoking and drinking behavior have different impacts on changes in BMI for females and males. Males' BMI decreases with smoking and increases 
with quitting smoking, but females' BMI increases with drinking alcohol and decreases with stopping drinking. Losing a partner during the ten year period decreases only the females' BMI, but gaining a spouse/partner is associated with increases in BMI for both genders. For married females and males, the change in spousal BMI is significantly positively related. Therefore, we find an evidence of positive relationship between spousal weights.

Information to adopt healthy behaviors and lifestyles through knowledge or understanding of the long term consequences of such behaviors is critical for better health of the citizens. Government action may also be warranted to correct the unintended health consequences of existing choices. Preventative interventions promoted by the government could be beneficial for choice of a healthier lifestyle. Understanding interactions between individual health-related behaviors and the set of determinants that contribute to such behaviors is a fundamental step in the design of effective interventions. Individuals should be encouraged to make positive life-enhancing health decisions on tobacco use, excessive alcohol consumption, and unhealthy diet - not only for Russia but all around the world. For example, increasing taxes on tobacco, smoke-free environments, and running mass media campaigns, do reduce smoking. In this light, the Russian government has banned cigarette ads and prohibited smoking in public buildings since the summer of 2010.

\section{Acknowledgement}

The author thanks Dr. Alison Burrell for very helpful discussions on the topic, Dr. Marian Rizov for help with data and the anonymous reviewers for their comments.

\section{References}

Averett S., Sikora A., \& Argys L. (2008). For better or worse: Relationship status and body mass index. Economics and Human Biology, 6, 330-349. http://dx.doi.org/10.1016/j.ehb.2008.07.003

Bobrova N., West R., Malyutina D., Malyutina S., \& Bobak, M. (2010). Gender Differences in Drinking Practices in Middle Aged and Older Russians. Alcohol and Alcoholism, 45(6), 573-580. http://dx.doi.org/10.1093/alcalc/agq069.

Cameron A., \& Trivedi P. (2005). Microeconometrics: methods and applications. Cambridge University Press.

Chou, S., Grossman M., \& Saffer H. (2004) An economic analysis of adult obesity: Results from the behavioral risk factor surveillance system. Journal of Health Economics, 23(3), 565-587. http://dx.doi.org/10.1016/j.jhealeco.2003.10.003

Christakis, N. A., \& Fowler, J. H., (2007). The spread of obesity in a large social network over 32 years. New England Journal of Medicine, 357(4), 370-379. http://dx.doi.org/10.1056/nejmsa066082

Cockerham, W. (2000). Health Lifestyles in Russia. Social Science and Medicine, 51, 
1313-1324. http://dx.doi.org/10.1016/s0277-9536(00)00094-0

Cockerham, W., Snead C. \& DeWaal D. (2002). Health Lifestyles in Russia and the Socialist Heritage. Journal of Health and Social Behavior, 43(1), 42-55. http://dx.doi.org/10.2307/3090244

Cooke L., \& Wardle, J. (2007). Depression and obesity. In: Steptoe A. (ed). Depression and Physical Illness. Cambridge University Press: Cambridge.

Cooper W. (1999). The Russian Financial Crisis of 1998: An Analysis of Trends, Causes, and Implications. Report for Congress Retrieved February 8, 2011 from http://congressionalresearch.com/98-578/document.php?study=The+Russian+Financial+ Crisis + of $+1998+$ An + Analysis + of + Trends + Causes + and + Implications

Ethan Cohen-Cole E., \& Fletcher J. (2008). Is Obesity Contagious? Social Networks versus Environmental Factors in the Obesity Epidemic. Journal of Health Economics, 27, 1382-1387. http://dx.doi.org/10.1016/j.jhealeco.2008.04.005

Greeno C., \& Wing R. (1994). Stress-Induced Eating. Psychological Bulletin, 115(3), 444-446. http://dx.doi.org/10.1037//0033-2909.115.3.444

Huffman S., \& Rizov M. (2007). Determinants of Obesity in Transition Economies: The Case of Russia. Economics and Human Biology, 5(3), 379-391. http://dx.doi.org/10.1016/j.ehb.2007.07.001

Huffman S., \& Rizov M. (2010). The Rise of Obesity in Transition: Theory and Empirical Evidence from Russia. Journal of Development Studies, 46(3), 1-22. http://dx.doi.org/10.1080/00220380903383230

Huffman W., Huffman, S., Tegene A., \& Rickertsen, K. (2010). The Economics of Obesity-Related Mortality among High Income Countries. Forum for Health Economics and Policy, 13(1). http://dx.doi.org/10.2202/1558-9544.1181

Jahns, L., Baturin A., \& Popkin, B. (2003). Obesity, diet, and poverty: trends in the Russian transition to market economy. European Journal of Clinical Nutrition, 57, 1295-1302. http://dx.doi.org/10.1038/sj.ejcn.1601691

Jeffery R., \&Rick, A. (2002). Cross-sectional and Longitudinal Associations between Body Mass Index and Marriage-Related Factors. Obesity Research, 10(8), 809-815. http://dx.doi.org/10.1038/oby.2002.109

Kalediene R., \& Petrauskiene J. (2004). Socio-economic transition, inequality, and mortality in Lithuania. Economics and human biology, 2(1), 87-95. http://dx.doi.org/10.1016/j.ehb.2003.12.001

Koziel S., Welon Z., Bielicki T., Szklarska A., \& Ulijaszek S. (2004). The effect of the economic transition on the body mass index of conscripts in Poland. Economics and human biology, 2(1), 97-106. http://dx.doi.org/10.1016/j.ehb.2003.12.002

Lakdawalla, D., Philipson T., \& Bhattacharya J. (2005) Welfare-enhancing technological 
change and the growth of obesity. American Economic Review, 95, 253-257. http://dx.doi.org/10.1257/000282805774670266

Nishitani N., \& Sakakibara H. (2006). Relationship of Obesity to Job Stress and Eating Behavior in Male Japaness Workers. International Journal of Obesity, 30, 528-533. http://dx.doi.org/10.1038/sj.ijo.0803153

Palosuo, H. (2000). Health-Related Lifestyles and Alienation in Moscow and Helsinki. Social Science and Medicine, 1325-1341. http://dx.doi.org/10.1016/s0277-9536(00)00095-2

Rashad, I., Grossman M., \& Chou S. (2006). The super-size of America: An economic estimation of body mass index and obesity in adults. Eastern Economic Journal 32(1), 133-148. http://dx.doi.org/10.3386/w11584

Sassi F., \& Hurst J. (2008). The Prevention of Lifestyle-related Chromic Diseases: An Economic Framework. OECD Health working paper NO.32. http://dx.doi.org/10.1787/243180781313

Staudigel, M. (2011). How (much) do Food Prices Contribute to Obesity in Russia. $\begin{array}{llll}\text { Economics Human } \text { and Biology, } & \text { 133-147. }\end{array}$ http://dx.doi.org/10.1016/j.ehb.2010.11.001

Stillman, S. (2006). Health and Nutrition in Eastern Europe and the Former Soviet Union during the Decade of Transition: A Review of Literature. Economics and Human Biology, 4, 104-146. http://dx.doi.org/10.1016/j.ehb.2005.04.005

Treml, Vladimir G. (1997). Soviet and Russian Statistics on Alcohol Consumption and Abuse. http://dx.doi.org/10.2139/ssrn.2293

Trogdon, J. G., Nonnemaker J., \& Pais J. (2008). Peer effects in adolescent overweight. Journal of Health Economics, 1388-1399. http://dx.doi.org/10.1016/j.jhealeco.2008.05.003

Voronina TA. (2009). From Soviet Cuisine to Kremlin Diet: Changes in Consumption and Lifestyle in Twentieth Century Russia. In Oddy D., P. Atkins and V.Amilien (eds.), Thi Rise of Obesity in Europe: a twentieth century food history. Ashgate Publishing Company: Burlington, VT.

World Health Organization WHO (2002). The World Health Report 2002: Reducing Risks, Promoting Healthy Life. Geneva, Switzerland, World Health Organization. http://dx.doi.org/10.1016/j.agecon.2003.11.006

Zohoori, N., Mroz T., Popkin B., Glinskaya E., Lokshin M., Mancini D., Kozyreva P., Kosolapov M., \& Swafford M. (1998). Monitoring the Economic Transition in the Russian Federation and its Implications for the Demographic Crisis - the Russian Longitudinal Monitoring Survey. World Development, 26(11), 1977-1993. http://dx.doi.org/10.1016/s0305-750x(98)00099-0 


\section{Copyright Disclaimer}

Copyright reserved by the author(s).

This article is an open-access article distributed under the terms and conditions of the Creative Commons Attribution license (http://creativecommons.org/licenses/by/3.0/). 